Biostatistics, National Institute of Mental Health and Neurosciences, Bangalore, India, and the Neuroepidemiology Branch, National Institute of Neurological Disorders, NIH, Bethesda, MD, USA. The ages ranged from 8 mos to 58 yrs with a childhood preponderance and $28 \%$ below 6 years. The male:female ratio was 2.65:1. Only $7 \%$ had a history of febrile convulsions. Complex partial seizures were the most frequent manifestation of HWE (67\%) and generalized tonic-clonic seizures occurred in 33\%. Spontaneous non-reflex epilepsy followed or preceded the onset of HWE in 30\%. A positive family history of epilepsy was obtained in 228 and for HWE in only 7\%. The avoidance of the hot water stimulus should be supplemented with anticonvulsant medication in therapy. (Satishchandra $\mathrm{P}$ et al. Hot-water epilepsy: a variant of reflex epilepsy in Southern India. Epilepsia Jan/Feb $1988 ; 29: 52-6)$.

COMIENT. The mechanism of $\mathrm{HWE}$ is unclear. A hot-air stimulus to the heads of patients failed to induce attacks. A kindling effect has been induced in rats by repeated exposure of the head to hot water (Klanenberg BJ, Sparber SB. Epilepsia 1984:25:292). Hot water applied to the abdomen induces fever and changes in cortical electrical activity of cats and kittens (Kashiwase Y. Brain Nerve (Tokyo) 1962;14:698). The body temperature of patients in the present study is not documented and fever induced by the hot water stimulus may explain some cases, especially in younger children.

Absence epilepsy evoked by thinking or talking about driving an automobile is an unusual example of reflex epilepsy also reported in the current issue of Epilepsia (Bencze KS et al. of the Dept of Neurology, University of South Florida, Tampa, FL).

\title{
DEGENERATIVE AND METABOLIC DISORDERS
}

\section{MONOAMINE METABOLITES IN RETT SYNDROME}

Cerebral metabolites of noradrenaline, dopamine and serotonin, y-aminobutyric acid, and 23 amino acids were present in normal concentrations in the CSF of 5 girls with Rett syndrome studied in the Depts of Pharmacology and Therapeutics, and Dept of Paediatrics, University of British Columbia, Vancouver, Canada. The authors doubt that any biochemical abnormalities have been clearly established as characteristic of the syndrome. (Perry TL, Dunn HG et al. Cerebrospinal fluid values for monoamine metabolites, $\mathrm{y}$-aminobutyric acid and other amino compounds in Rett syndrome. $\mathrm{J}$ Pediatr Feb $1988 ; 112: 234-8$ ).

Comearr. A previous report of low CSF levels of monoamine metabolites in patients with Rett syndrome (Zoghbi HY et al. N Engl J Med 1985;313:921) is not supported by the present study. Hyperamonemia reported originally by Rett is another suggested biochemical basis for the syndrome unconfirmed in subsequent reports. The lack of uniformity of these findings suggests that Rett syndrome is a nonspecific entity with more than one etiology.

\section{INFANITLE REFSUM DISEASE}

Two patients with infantile Refsum (phytanic acid storage) disease were

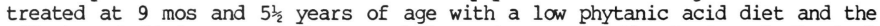
effects studied over a 2-yr period or longer in the Depts of Chemical Pathology, Neurology and Histopathology, Adelaide Children's Hospital, and the Dept of Neurology, Prince of Wales Children's Hospital, New South Wales, 